\title{
Clinical, Demographic and Psychological Predictors of Quality of Life in Patients with Osteoarthritis
}

\author{
L. Libova (Lubica Libova)ำ A. Solgajova (Andrea Solgajova)², G. Vorosova (Gabriela \\ Vorosova) $)^{2}$, D. Zrubcova (Dana Zrubcova) $)^{2}$, T. Sollar (Tomas Sollar) ${ }^{3}$, S. Mrazova \\ (Simona Mrazova) ${ }^{1}$, J. Debnarova (Jana Debnarova) ${ }^{1}$, P. Zubata (Petra Zubata) ${ }^{1}$, \\ K. Pechova (Katarina Pechova) ${ }^{1}$
}

${ }^{1}$ Department of Nursing, Faculty of Health and Social Work, Nove Zamky,

Original Article St. Elizabeth University of Health and Social Work Bratislava, SK.

${ }^{2}$ Department of Nursing, Faculty of Social Sciences and Health Care, Constantine the Philosopher University in Nitra, SK.

${ }^{3}$ Institute of Applied Psychology, Faculty of Social Sciences and Health Care, Constantine the Philosopher University in Nitra, SK.

\section{E-mail address:}

lubica.libova@gmail.com

\section{Reprint address:}

Lubica Libova

St. Elizabeth University of Health and Social Work Bratislava

Slovenska 11

94052 Nove Zamky

Slovakia

Source: Clinical Social Work and Health Intervention

Volume: 12

Issue: 4

Pages: $62-68$

Cited references: 33

\section{Reviewers:}

Selvaraj Subramaniam

Kuala Lumpur

Gabriela Lezcano

University of California, San Francisco, USA

\section{Keywords:}

Osteoarthritis. Quality of life. Anxiety. Pain. Care..

\section{Publisher:}

International Society of Applied Preventive Medicine i-gap

CSWHI 2021; 12(4): 62 - 68; DOI: 10.22359/cswhi_12_4_07 (C) Clinical Social Work and Health Intervention

\section{Abstract:}

Background: To select the appropriate strategies for treatment of osteoarthritis, it is advisable to assess not only the functional disorders but also their psychological and social aspects. The study objective was to examine the relationship between quality of life in patients with osteoarthritis and selected clinical, demographic and psychological factors. Sample: The sample consisted of 49 respondents with a medical diagnosis of osteoarthritis of the hip. 


\section{Introduction}

Osteoarthritis is a degenerative disease which affects a joint cartilage followed by a subchondral bone, joint capsule, synovial membrane, peri-articular muscles and tendon-to-bone insertions (Lukacova, Lukac, 2015). It is a common disease whose incidence has been increasing in both genders, particularly with age (McAlindon, et al., 1999). The causes of the disease may vary. Osteoarthritis and its prevalence in people older than 65 years of age is described as the most frequently present gonarthrosis, then osteoarthritis of small joints in hands and coxarthrosis (Lukac, Lukacova, Rovensky, 2004).

The disease is manifested by pain, and functional disorder and thickening of a joint (Lukacova, Lukac, 2015). Physical disabilities and an inability to perform the activities of daily living occur in patients because of the disorders of the locomotor functions (gait, ascending or descending, stairs, sitting, and standing) (Rogind, et al. 1998).

In general, chronic pain and psychological disorders are present in patients with osteoarthritis (Goldenberg, 1989). Often, depression and anxiety worsen, particularly related to long-term pain (Lukac, Lukacova, Rovensky, 2004). In comparison with depression, anxiety is often an overlooked psychological comorbid symptom of osteoarthritis (Marks, 2015). Chronic pain increases comorbid anxiety and depression in patients with osteoarthritis (Hansen, Streltzer, 2005; He et al., 2008).

Recent studies have shown that also anxiety levels and depression can alter threshold perceptions of pain (Hansen, Streltzer, 2005). Analysis of 13 studies which focused on the prevalence of anxiety and depression in patients with osteoarthritis found that their prevalence correlated with pain intensity, severity and location (Sharma et al., 2016). The results of many studies suggest that patients with osteoarthritis accompanied by anxiety state more intensive pain, and less optimal outcomes in treatment are found in them (Marks, 2015). Attention has been paid to research and diagnosis of anxiety in patients with osteoarthritis because new information will contribute to favorable prospects in treatment and care for patients with osteoarthritis (Roy-Byrne et al., 2008; Marks, 2015).

Treatment for osteoarthritis must be complex.
It requires patient's participation, and interdisciplinary cooperation between rheumatologists, orthopedists, physiatrists, general practitioners and other specialists. The goal of treatment is to slow down the progression of the disease, relieve pain, suppress inflammation, and maintain and improve the quality of life. Physical therapy is an important part of treatment (Lukac, Lukacova, Rovensky, 2004).

Osteoarthritis affects human society as a whole. Besides pain and functional disorders, it causes other health problems. A more sedentary lifestyle contributes to an increase in occurrence of cardiovascular problems, osteoporosis, obesity, and psychological problems (Ozcetin et al., 2007). The disease is characteristic of an onset of other comorbid difficulties which restrict an ability to perform activities of daily living, and thus significantly reduce quality of life in patients (Montin et al., 2007; Kawano et al., 2015). An assessment of quality of life demonstrates an influence of chronic diseases on the patient's condition. To select the appropriate treatment strategies, it is necessary to assess not only functional disorders but also psychological and social aspects of these disorders (Ozcetin et al., 2007).

\section{Objective}

The study objective was to examine the relationship between quality of life in patients with osteoarthritis and selected clinical (pain level, disease duration), demographic (gender, age) and psychological (anxiety) factors.

\section{Sample and methods}

The research was conducted as a prospective cross-sectional descriptive study. A target group included the patients with the medical diagnosis osteoarthritis of hip (in accordance with the ICD10, code M-16.0 - 16.9) hospitalized at the Orthopedic Clinic in Nitra. The sampling criteria included patients with an indicated surgical treatment and a respondent's informed consent with research. The sample consisted of 49 (100\%) respondents, including $38.8 \%$ of men and $61.2 \%$ of women. The respondents' age ranged from 38 to 79 years $\left(\mathrm{M}_{\mathrm{age}}=59.24 ; \mathrm{SD}_{\mathrm{age}}=8.46\right)$, with an average disease duration 3.12 years (SD \% 2.9).

The data were collected from October 2015 to February 2016. Measurements were conducted 
by a nurse trained by a psychologist for administration of the used scales. The research was approved by the Hospital Ethics Committee.

The questionnaire SF 36 was used to measure quality of life, and was supplemented with demographic (gender, age) and clinical (disease duration) items. The HADS (Hospital Anxiety and Depression Scale) was used to measure anxiety and the Numeric Pain Rating Scale was used to measure pain levels.

The questionnaire SF 36 is generally sensitive to all physical health problems and also to general mental health. The questionnaire can be used to detect quality of life in a wide range of diseases, for example schizophrenia, breast cancer, depression, asthma, mood disorders and anxiety states, carpal tunnel syndrome, and many others (Ware, Sherbourne, 1992). The questionnaire consists of 36 items divided into eight dimensions: physical functioning; physical limitations; bodily pain; general health; vitality; social functioning; emotional issues; mental health. These dimensions are divided into two areas: 1) general physical health and 2) general mental health (Ware, Kosinski, 2001). The questionnaire contains one item which is not included in any of the areas. This item describes health in general compared to one year ago. In the questionnaire, the higher scores suggest a better HRQL (Health-Related Quality of Life) index. The score ranges from 0 to 100 points. The scores below 50 can be interpreted as below the norm of the general population. The lower SF 36 scores suggest, for example, worse health status (Ware, Sherbourne, 1993).

The HADS (Hospital Anxiety and Depression Scale) is a gold standard to measure anxiety and depression in patients (Zigmond, Snaith, 1983). It is a 14-item self-assessment scale which measures patient's mental status in a recent week. 7 items relate to anxiety and 7 relate to depression. In the study, we used a short version of the scale - the version HADS-A to measure anxiety. Each item is rated on a 4-point scale. A sum of each rated item is a total score. The scores $0-7$ mean a status without anxiety, $8-10$ a cut off for anxiety, and $11-21$ severe anxiety (McDowell, 2006). The scale has good reliability (Cronbach $\alpha=0.75$ ) (Bjelland et al., 2002; McDowell, 2006).

The Numeric Pain Rating Scale measures pain intensity. The scale is one of the most commonly used scales to assess pain. The administration of the scale is not difficult. It is a segmented numeric scale with whole numbers $0-$ 10 , with 0 representing "no pain" and 10 representing "worst pain". The scale has good reliability (Cronbach $\alpha=0.75-0.89$ ) (Farrar et al., 2001; Rodriguez, 2001).

We used the software SPSS 22.0 for statistical analysis of the data. The arithmetic mean, standard deviation, frequencies and percentages were used as descriptive characteristics. To evaluate the results, we used a multiple linear regression analysis (the Enter method) which measures statistical significance of all predictors and a total amount of variance explaining a dependent variable (Tabachnick, Fidell 2007).

\section{Results}

An average level of general physical health in the patients with osteoarthritis was 34.0 (SD = 14.8) and of general mental health 49.9 (SD = 19.2). An average pain level was $7.39(\mathrm{SD}=1.2)$. The anxiety level was $9.08(\mathrm{SD}=4.4)$ in average; $39 \%$ of the patients were without anxiety, increased anxiety was found in $16 \%$ of the patients, and severe anxiety was found in $45 \%$ of the patients.

We conducted the analysis in 2 models for a dependent variable: general physical health and general mental health.

Table 1 General evaluation of prediction models of quality of life in patients with osteoarthritis

\begin{tabular}{|l|c|c|c|c|}
\hline & $\mathbf{R}$ & Adj $^{2}$ & $\mathbf{F}$ & $\mathbf{P}$ \\
\hline $\begin{array}{l}\text { Model 1 } \\
\text { (DV: General } \\
\text { physical health) }\end{array}$ & 0.516 & 0.267 & 3.126 & .017 \\
\hline $\begin{array}{l}\text { Model 2 } \\
\text { (DV: General } \\
\text { mental health) }\end{array}$ & 0.692 & 0.479 & 7.909 & $<.001$ \\
\hline
\end{tabular}

NB: Predictors: Gender, Age, Disease duration, Pain, Anxiety

The $1^{\text {st }}$ model evaluates the predictors of general physical health. The model is statistically significant $\left(F=3.1 ; p=.017\right.$, Adj $\left.R^{2}=0.27\right)$, the variables explain almost $27 \%$ of variability of 
Table 2 Regression coefficients of predictors of 2 prediction models of quality of life in patients with osteoarthritis

\begin{tabular}{|c|c|c|c|c|c|c|}
\hline & & B & $\mathrm{SE}(\mathrm{B})$ & $\beta$ & $\mathrm{t}$ & $P$ \\
\hline \multirow{5}{*}{$\begin{array}{l}\text { Model } 1 \\
\text { (General } \\
\text { physical } \\
\text { health) }\end{array}$} & Gender & -3.243 & 4.099 & -.107 & -.791 & .433 \\
\hline & Age & .126 & .244 & .072 & .519 & .606 \\
\hline & $\begin{array}{l}\text { Disease } \\
\text { duration }\end{array}$ & .183 & .763 & .036 & .241 & .811 \\
\hline & Pain & .659 & 1.606 & .055 & .410 & .684 \\
\hline & Anxiety & -1.674 & .473 & -.499 & -3.541 & .001 \\
\hline \multirow{5}{*}{$\begin{array}{l}\text { Model } 2 \\
\text { (General } \\
\text { mental } \\
\text { health) }\end{array}$} & Gender & -.335 & 4.461 & -.009 & -.075 & .941 \\
\hline & Age & .090 & .265 & .040 & .340 & .736 \\
\hline & \begin{tabular}{|l|} 
Disease \\
duration
\end{tabular} & .297 & .830 & .045 & .358 & .722 \\
\hline & Pain & -.400 & 1.748 & -.026 & -.229 & .820 \\
\hline & Anxiety & -3.066 & .514 & -.707 & -5.960 & $<.001$ \\
\hline
\end{tabular}

NB: B - unstandardized regression coefficient, $\mathrm{SE}(\mathrm{B})$ - standard error of unstandardized regression coefficient, $\quad \beta$ - standardized regression coefficient, $t$ - t-test, $p$ - statistical significance

general physical health in the patients with osteoarthritis (Table 1). Out of all studied variables (gender, age, disease duration, pain, anxiety), only one variable - anxiety - explains general physical health $(\beta=-.499 ; \mathrm{p}=.001)$ (Table 2$)$.

The $2^{\text {nd }}$ model evaluates the predictors of general mental health of the same variables. The model is statistically significant $(\mathrm{F}=7.9 ; \mathrm{p}<$ .001 , Adj $\left.\mathrm{R}^{2}=0.48\right)$, the variables explain almost $48 \%$ of variability of general mental health (Table 1). The only significant predictor, as in the first model, is anxiety $(\beta=-.707 ; p=.001)$ (Table 2).

\section{Discussion}

In the study, we measured quality of life in the patients with osteoarthritis. An assessment of quality of life is an inherent part of the process of care and treatment in patients with osteoarthritis (Lukac, Lukacova, Rovensky, 2004; Jakobsson, Hallberg, 2002), because it demonstrates an influence of functional disorders on all aspects of patient's life. Jakobsson \& Hallberg (2002) analyzed 17 studies which measured quality of life in patients with osteoarthritis. In the analyzes, they found that none of the studies had included respondents older than 75 years of age, which they considered a serious limitation, because it is important to address the age group of patients older than 75 years, too. In our study, we also reflected on the request; the respondents' age ranged from 38 to 79 years $\left(\mathrm{M}_{\text {age }}=59.24 ; \mathrm{SD}_{\text {age }}\right.$ $=8.46$ ).

In the study, we found that the average level of general physical health in the patients with osteoarthritis was below 50 , i.e. below the norm of the general population. The lower score of SF 36 suggests worse health status. Shalaby \& ElSayed (2017) assessed quality of life in patients with gonarthrosis with the use of the questionnaire SF 36 and found scores lower than 50 in all domains except the domain mental health. Similar findings are stated by Ferreira et al. (2015); in the study on quality of life in female patients with gonarthrosis they found lower quality of life in comparison with the general population.

Several authors focus on research in the area of measurement of quality of life in patients with osteoarthritis, particularly related to: pain (Jakobsson, Hallberg, 2002; Creamer, LethbridgeCejku, Hochberg, 1999), demographic factors (Creamer, Lethbridge-Cejku, Hochberg, 1999), and depression and anxiety (Blixen, Kippes, 1999; Creamer, Lethbridge-Cejku, Hochberg, 
1999; Ozcetin et al., 2007; Montin et al., 2007; Marks, 2015; Ferreira et al., 2015; Shalaby, ElSayed, 2017).

In the rresearch, we focused on studying the relationship between quality of life in patients with osteoarthritis and pain level, disease duration, gender, age, and anxiety level. We found that pain level was much closer to the value "worst (unbearable) pain". The average anxiety level meant a cut off of anxiety, and similar findings on anxiety level in this group of patients are confirmed by other authors, too (Montin et al., 2007; Shalaby, El-Sayed, 2017). In our sample, anxiety was present in $61 \%$ of respondents; the studies state anxiety in $50 \%$ of patients with osteoarthritis (Marks, 2011; Gandhi et al., 2015).

The studied clinical (pain level, disease duration), demographic (gender, age), and psychological (anxiety) factors explained the statistically significant relationships in both areas of quality of life (general physical health and general mental health), more in the area of general mental health. Jakobsson \& Hallberg (2002) found that pain, functional limitation and higher age decrease quality of life in patients, and thus they support our findings.

We found that, out of the 5 studied variables, independently only anxiety levels predict general physical and mental health. The worse anxiety the patients experienced, the worse assessment of their physical and mental areas of quality of life. Experiencing anxiety is more manifested in the area of a psychological aspect of quality of life; however, even an influence of anxiety on a physical aspect of quality of life is not negligible. Also, according to Ozcetin et al. (2007), there is a strong negative correlation between anxiety and quality of life in patients with osteoarthritis. Marks (2015) states that anxiety and depression negatively influence quality of life in patients with osteoarthritis. Lunghi, Miller \& McQuillan (1978) state that patients with osteoarthritis with higher anxiety levels had worse health status. Axford et al. (2010) state that anxiety levels in patients with osteoarthritis correlated with functional disability level.

According to our findings and findings by other studies, we can consider anxiety to be a significant predictor of quality of life in patients with osteoarthritis. Anxiety accompanying a dis- ease influences physical, functional and social well-being and health status of patients (Castano et al., 2015). It is a predictor which is to be taken into account in treatment and care in order to achieve optimal outcomes in the patient. Marks (2015) states that patients with osteoarthritis with anxiety experienced more pain, visited hospital more often, used more drugs, and their recuperation took longer. In the present, the treatment of osteoarthritis has a lower tendency to focus on anxiety reduction despite the fact that anxiety is detected in up to 50\% of patients (Marks, 2013; Gandhi et al., 2015). Several studies confirm the need to assess patients' mental status in order to optimize functional outcomes in patients with osteoarthritis (Tallon, Chard, Dieppe, 2000).

\section{Conclusions}

To select the appropriate treatment and care strategies for patients with osteoarthritis, it is necessary to assess their quality of life (Ozcetin et al., 2007), because it is a disease which is typical of an onset of comorbid difficulties which restrict an ability to perform the activities of daily living, and thus influence various aspects of patients' life. Also, many studies state it is necessary to assess anxiety levels in order to optimize functional outcomes in patients with osteoarthritis (Tallon, Charp, Dieppe, 2000). The findings in our study also suggest that anxiety accompanying the disease influences both physical and mental status in patients (Castano et al., 2015). Particularly, the multidisciplinary approach and psychological support are recommended in care for patients with osteoarthritis.

\section{References}

1. AXFORD J et al.( 2010) Prevalence of anxiety and depression in osteoarthritis: use of the Hospital Anxiety and Depression Scale as a screening tool. In Clin Rheumatol. ISSN 1434-9949, 2010, vol. 29, no.11, pp. 12771283.

2. BJELLAND I et al. (2002) The Validity of the Hospital Anxiety and Depression Scale; an updated review. In Journal of Psychosomatic Research. ISSN 0022-3999, 2002, vol.52, no. 2, pp. 69-77.

3. BLIXEN C E, KIPPES C (1999) Depression, social support, and quality of life in older adults with osteoarthritis. In Image J Nurs 
Sch. ISSN 0743-5150, 1999, vol.31, no. 3, pp. 221-226.

4. CASTANO C A et al. (2015) Clinical profile, level of affection and therapeutic management of patients with osteoarthritis in primary care: the Spanish multicenter study EVALUA. In Rheumatol. Clinics. ISSN 1536-7355, 2015, vol.41, no.2, pp. 259-299.

5. CREAMER P, LETHBRIDGE-CEJKU M, HOCHBERG M C (1999) Determinants of pain severity in knee osteoarthritis: effect of demographic and psychosocial variables using 3 pain measures. In J Rheumatol. ISSN 0380-0903, 1999, vol.26, no.8, pp. 17851792.

6. FARRAR J T et al. (2001) Clinical importance of changes in chronic pain intensity measured on an 11-point numerical pain rating scale. In Pain. ISSN 0304-3959, 2001, vol. 94, no.2, pp.149-58.

7. FERREIRA A H et al. (2015). Investigation of depression, anxiety, and quality of life in patients with knee osteoarthritis: a comparative study. In Rev Bras Reumatol. ISSN 1809-4570, 2015, vol. 55, no.5, pp. 434-438.

8. GANDHI R et al. (2015) Depression and the overall burden of painful joints: an examination among individuals undergoing hip and knee replacement for osteoarthritis. In Arthritis. ISSN 2167-7921, 2015, vol. 15, doi: $10.1155 / 2015 / 327161$.

9. GOLDENBERG D L (1989) Psychiatric and psychologic aspects of fibromyalgia syndrome. In Rheum Dis Clin North Am. ISSN 0889-857X, 1989, vol.15, no.1, pp. 105-114.

10. HANSEN G R, STRELTZER J (2005) The psychology of pain. In Emerg Med Clin North Am., ISSN 1558-0539, 2005, vol. 23, no.2, pp. 339-348.

11. HE Y et al. (2008) Mental disorders among persons with arthritis: results from the World Mental Health Surveys. In Psychol Med. ISSN 1469-8978, 2008, vol. 38, no.11, pp. 1639-1650.

12. JAKOBSSON U, HALLBERG I R (2002) Pain and quality of life among older people with rheumatoid arthritis and/or osteoarthritis: a literature review. In Journal of Clinical Nursing. ISSN 1365-2702, 2002, vol. 11, no.2, s. pp. 430-443.

13. KAWANO M M et al. 2015. Assessment of
Quality of Life in Patients with Knee Osteoarthritis. In Acta Ortop Bras. ISSN, 2015, vol. 23, no.6, pp. 307-310.

14. LUKAC, J., LUKACOVA, O., ROVENSKY, J (2004) Osteoarthitis in terms of etiopahogenesis, diagnosis and clinical picture. In Suc Klin Pr. ISSN 1804-9427, 2004, vol 1, no.2, pp. 12-18.

15. LUKACOVA O, LUKAC J (2015) Treatment of osteorathiris. In Via pract. ISSN 13364790, 2015, roč.12, č.3, s. 114-121.

16. LUNGHI M E, MILLER P M, McQUILLAN W M (1978) Psycho-social factors in osteoarthritis of the hip. In J Psychosom Res. ISSN 0022-3999, 1978, vol.22, no.1, pp. 5763.

17. MARKS J (2015) Anxiety and its Impact on Osteoarthritis Pain: An Update. In Rheum Dis Treat. ISSN 2469-5726, 2015, vol.1, no.2, p.1-15.

18. MARKS R (2013) Anxiety in Disabling Osteoarthritis: Implications for Research and Practice. In Aging Sci. ISSN 2329-8847, 2013, vol. 1, no.3, doi: 10.4172/23298847.1000e p. 105.

19. MARKS R (2016) Prevalence of anxiety symptoms and it impact in people with osteoarthritis: An update. In Int. J. Clin. Rheumatol. ISSN 1758-4272, 2016, vol. 11, no.4, pp. 42-49

20. McALINDON T E et al. (1999) Level of physical activity and the risk of radiographic and symptomatic knee osteoarthritis in the elderly: the Framingham Study. In Am J Med. ISSN 1555-7162, 1999, vol.106, no.2, pp. 151-157.

21. McDOWELL I (2006) Measuring Health : A Guide to Rating Scales. 3rd Ed. New York: Oxford University Press, 2006. p. 748. ISBN 13 978-0-19-516567-8.

22. MONTIN L et al. (2007) Anxiety and healthrelated quality of life of patients undergoing total hip arthroplasty for osteoarthritis. In Chronic Illness. ISSN 17459206, 2007, vol.3, no.3, pp. 219-227.

23. OZCETIN A et al. (2007) Effects of depression and anxiety on quality of life of patients with rheumatoid arthritis, knee osteoarthritis and fibromyalgia syndrome. In West Indian Med J. ISSN 0799-5199, 2007, vol. 56, no.2, pp. 122-129. 
24. RODRIGUEZ C S (2001) Pain measurement in the elderly: a review. In Pain Manag Nurs. ISSN 1524-9042, 2001, vol. 2, no.2, pp. 3846.

25. ROGIND H et al. (1998) The effects of a physical training program on patients with osteoarthritis of the knees. In Arch Phys Med Rehabil. ISSN 0003-9993, 1998, vol.79, no.11, pp. 1421-1427.

26. ROY-BYRNE P P et al. (2008) Anxiety disorders and comorbid medical illness. In Gen Hosp Psychiatry. ISSN 0163-8343, 2008, vol.30, no.3, pp. 208-225.

27. SHALABY A S, EL-SAYED A S (2007) Anxiety, depression, and quality of life in patients with knee osteoarthritis before and after knee joint replacement. In Egyptian Journal of Psychiatry. ISSN 0254-136X, 2017, vol. 38, no.1, pp. 8-12.

28. SHARMA A et al. (2016) Anxiety and depression in patients with osteoarthritis: impact and management challenges. In Open Access Rheumatology: Research and Reviews. ISSN 1179-156X, 2016, vol.8, no.1, pp. 103-113.

29. TABACHNICK B G, FIDELL L S (2007) Using Multivariate Statistics. 5th ed. Boston: Pearson Education Inc., 2007. p. 980. ISBN 978-0321056771.

30. TALLON D, CHARD J, DIEPPE P (2000) Exploring the priorities of patients with osteoarthritis of the knee. In Arthritis Care Res. ISSN 2151-4658, 2000, vol.13, no.5, pp. 312319.

31. WARE J E, KOSINSKI M (2001) $S F-36$ Physical and Mental Health Summary Scales: A Manual for Users of Version 1.2 $2^{\text {nd }}$ Ed.; Lincoln, RI: QualityMetric Inc., 2001.

32. WARE J E, SHERBOURNE C D (1992) The MOS 36-item short-form health survey (SF36). Conceptual framework and item selection. In Med Care. ISSN 1537-1948, 1992, vol. 30, no.6, pp. 473-483.

33. ZIGMOND A S, SNAITH R P (1983) The Hospital Anxiety and Depression Scale. In Acta Psychiatr Scand. ISSN 1600-0447, 1983, vol.67, no.5, pp. 361-370. 